\title{
Equity and financing for sexual and reproductive health service delivery: current innovations
}

\author{
Dominic Montagu, Maura Graff
}

\begin{abstract}
National and international decisions on financing for sexual and reproductive health $(\mathrm{SRH})$ services have profound effects on the type, unit costs and distribution of $\mathrm{SRH}$ commodities and services produced, and on their availability and consumption. Much international and national funding is politically driven and is doing little for equity and quality improvement. Financing remains a significant challenge in most developing countries and demands creative responses. While no "one-size-fits-all" solution exists, there are numerous ongoing examples of successful innovations, many of which are focusing on resource pooling and on purchasing or subsidising $\mathrm{SRH}$ services.

In this article we have used interviews, grey literature and presentations made at a range of recent public fora to identify new and innovative ways of financing $\mathrm{SRH}$
\end{abstract}

services so as to increase equity in developing countries. Because SRH services are often of low value as a personal good but high value as a public good, we summarise the issues from a societal perspective, highlighting the importance of financing and policy decisions for SRH services. We provide a structured overview of what novel approaches to financing appear to have positive effects in a range of developing countries. Targeting, government payment mechanisms, subsidy delivery and co-financing for sustainability are highlighted as showing particular promise. Examples are used throughout the article to illustrate innovative strategies.

Keywords developing countries, equity, finance, service delivery, sexual and reproductive health

J Fam Pann Reprod Health Care 2009; 35(3): 145-149

(Accepted 23 October 2008)

\section{Background}

Demand for many sexual and reproductive health (SRH) services is elastic: a small increase in price to the consumer results in a large reduction in the uptake of services (Figure 1). ${ }^{1}$ At the same time, however, SRH services have large positive externalities and societal value, which is why they have been a high priority for international and some national funding, effectively subsidising the price to the consumer. This is true in both developed and developing countries; however, the issue of financing in developing countries is often more dependent upon proactive financing innovations. While nearly all high-income countries have national health financing systems in place, in low-income countries this is not the case. In 2004, out-of-pocket expenditures constituted the greatest source (42\%) of financial resources for SRH in developing countries. ${ }^{2}$ Targeting financing and policy can therefore have a great impact on access and quality of SRH services in developing countries.

National and international decisions on financing have profound effects on the type, unit costs and distribution of SRH commodities and services produced, and on their availability and consumption. Often, these decisions are driven by political goals rather than goals of efficacy, equity or social justice, and can have far reaching unintended consequences. These consequences can be felt within national borders or, when the political goals are donor-driven, can have importance far beyond the immediate targets of their initiators. 3,4

At the international level, the preoccupation with HIV has resulted in a 10-fold increase in HIV funding from

\section{Global Health Sciences, Global Health Group, University of California, San Francisco, CA, USA \\ Dominic Montagu, MBA, DrPH, Assistant Professor \\ School of Public Health, University of California, Berkeley, CA, USA \\ Maura Graff, MPH, Researcher}

Correspondence to: Dr Dominic Montagu, Global Health Sciences, Global Health Group, University of California, San Francisco, 50 Beale Street, Suite 1200, San Francisco, CA 94105-1823, USA.

E-mail: montagud@globalhealth.ucsf.edu

\section{Key message points}

- Financing sexual and reproductive health services, in ways that achieve equity of access and improve quality, remains a significant challenge in developing countries and demands creative responses.

- Although no single financing mechanism is applicable to all settings, successful innovations include targeting, expanding government payment mechanisms, subsidy delivery and co-financing for sustainability.

1996 to 2004,5 while funding for family planning, non-HIV reproductive health and research are stagnant or declining. Family planning assistance has fallen significantly since 1998.6

\section{National policies on access and reducing financial barriers}

Changes in national taxation policies regarding SRH have the potential for large positive effects. Prior to the 1994 ICPD meeting in Cairo, the Mexican government reduced tariffs on imported contraceptives. Taxes on condoms decreased from $45 \%$ to $10 \%$ between 1988 and 1991, and the subsequent price reduction to consumers is estimated to have contributed to a $25 \%$ increase in condom sales during $1990 .{ }^{7}$

Policy decisions to provide or withhold approval for specific drugs can have important, though often difficult to quantify, effects on access to care. In Nigeria, India and Tanzania, the governments' decisions to approve the registration of misoprostol for postpartum hemorrhage $(\mathrm{PPH})$ prevention and treatment has the potential for large and positive impact on the reproductive health of women for whom alternative management of $\mathrm{PPH}$, such as oxytocin, is unavailable. Because misoprostol does not require formal training to administer and is stable for long periods at room temperature it offers a way of reaching poor populations without the need for new infrastructure. 8 The significance of a policy change can be easily inferred: in sub-Saharan Africa the maternal mortality rate was 900 per 100000 in 2005, with PPH accounting for approximately $25 \%$ of those deaths. ${ }^{8-10}$ 


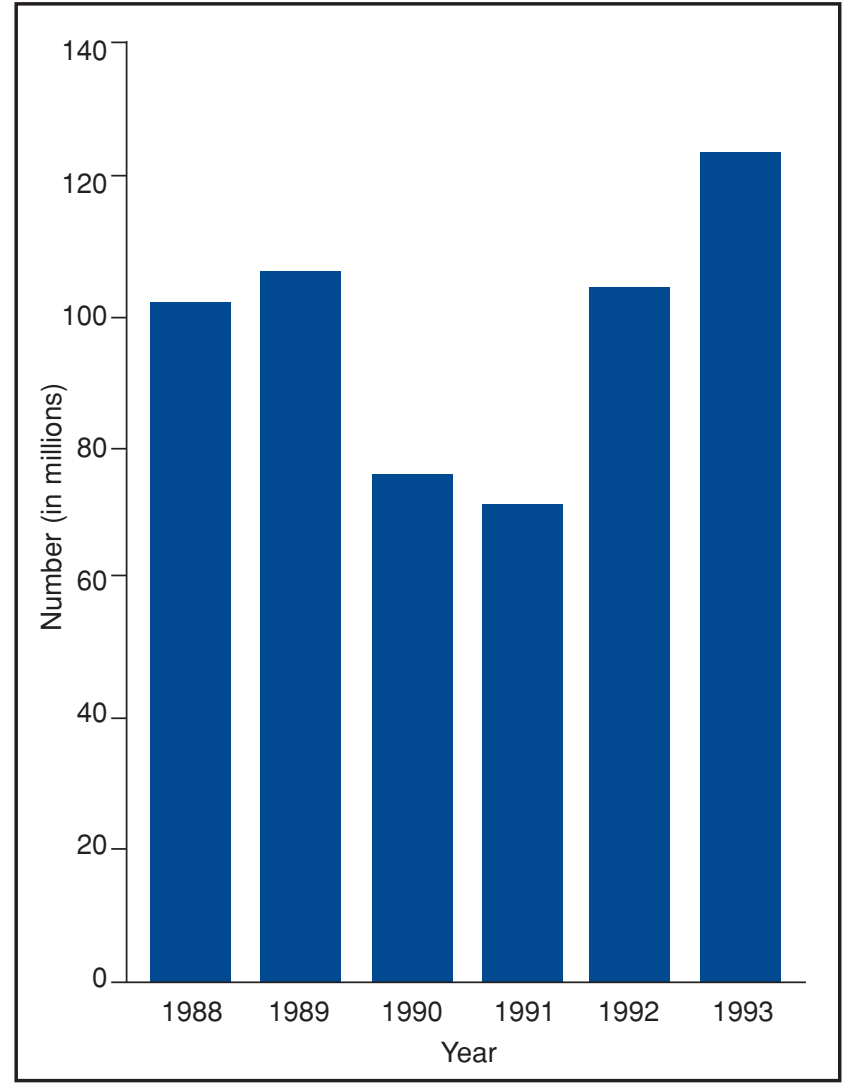

Figure 1 Annual sales of Raja condoms, social marketing project, Bangladesh, 1988-1993. Source: Population Services International, annual sales reports. The Elasticity of Demand for Contraception: the graph illustrates year-on-year condom sales, and the effect of a $60 \%$ increase in contraceptive prices implemented in 1990, and rescinded in 1992. Similar decreases occurred for other contraceptives during the same period. Figure reproduced from Ciszewski and Harvey ${ }^{1}$ with the kind permission of the authors

\section{National policies on direct financing}

As with international assistance, national decisions on financing for SRH are often determined by political considerations. The effectiveness and equity of SRH service coverage in low-income countries is determined by central-level policymakers and foreign donors, not by local-level providers. The influence of politics in funding priorities is particularly apparent in countries where there are significant differences in sources of SRH services between urban and rural populations. In Ghana, for example, the private sector supplied $54 \%$ of the couple years of protection (CYPs) in 2003. Demographic and Health Survey data reveal that the majority of public sector CYPs come from urban hospitals and clinics providing intrauterine devices, sterilisations, injections and implants. Pharmacies and chemical sellers are the largest source within Ghana's private sector and the most recent reported source of family planning for $39 \%$ of all contraceptive users, supplying mostly pills and condoms. Public financing for SRH services in this example has limited benefits for the poor because it is directed primarily at services that are delivered by providers in urban settings serving higher income clientele. Intentionally or not, the central decisions on what services would be financed by the national family planning programme effectively defined where services would be provided, and to whom.

Long-term family planning methods are frequently given priority through government-supported initiatives because they are more cost-effective at reducing fertility, but this is to the detriment of the poor who often live in areas where such services are of low quality or unavailable.
Exclusively subsidising government or non-governmental organisation (NGO) delivery channels can exclude adolescents and other populations who preferentially seek family planning services from private providers because of greater perceived privacy and other non-financial reasons. ${ }^{11,12}$ Those services that are more commonly paid for directly by beneficiaries - treatment of sexually transmitted infections (STIs), abortion services, normal deliveries - are correspondingly more likely to be delivered by providers who are not subsidised by the government, and for whom government oversight of quality is lax or non-existent.

\section{Innovations}

As illustrated above, any analysis of equity and financing must assess what services are being financed (treatment/prevention; long-term/short-term family planning commodities), where services are provided (urban/rural, hospital/outpatient) and who is providing them (formal clinical staff/informal healers; public/private). Within these broad areas of activity there are numerous opportunities for innovation that can lead to increased coverage, equity of access, and use of SRH services. Current innovations in SRH financing fall broadly into four, sometimes overlapping categories: targeting, expansion of government services, subsidy delivery and sustainability.

\section{Innovations in targeting}

Targeting benefits is a critical component of SRH services because of how often they are subsidised and unevenly accessible to the poor or geographically remote. Assuring that health care financing reaches disadvantaged populations is never easy. This is particularly challenging when the services to be provided are not related to an evident need (e.g. cataracts), an urgent event (e.g. emergency care), a national risk (e.g. infectious disease epidemics) or those easily addressed by a contained vertical intervention (e.g. immunisation). Delivering equitable SRH services requires higher levels of sustained accessibility and client-based programmes than the examples above because even minor access barriers related to distance, opening hours or being out of stock can deter uptake. Targeting financial support to assure that programmes are responsive to population and subpopulation needs, whether for full or partially subsidised services, often requires a system-wide response.

Some recent innovations in targeting of SRH financing and care have come through better identification of need, and through the use of lower-level providers to extend subsidised services to groups not served by more formal national care systems.

The Cambodia Health Equity Funds provide an example of community-based identification of need where communities are engaged to supplement governmental propoor initiatives. ${ }^{13}$ Governments and international NGOs benefit from local knowledge obtained by engaging community leaders and grassroots organisations. This onthe-ground awareness of need is particularly important for targeting transient and informal populations where local officials are less likely to have information on the needs and resources of population members.

Lower-level providers are often the primary source of SRH services, particularly in rural and poor-urban settings. Self-treatment through pharmacies is the primary source of outpatient care in many countries. One report from Uganda notes that " $57 \%$ of the population will not encounter either a nurse or physician in their lifetime". ${ }^{14}$ If financing is to be effective at reaching the poor, it must be used to improve more than just government-provided services. 
Most care in India and Bangladesh is delivered through rural medical practitioners (RMPs) - untrained or only partially trained sellers of goods, advice and medical services. In the Indian states of Bihar and Jarkhand the Janani programme has enrolled more than 35000 RMPs into a franchise network with regular support, re-supply of commodities and consumables, and a referral system to nearby clinicians within the franchise who are able to provide higher-level clinical services. In the villages where most Biharis live there is no access to governmentsupported medical care. RMPs within the Janani programme provide a range of SRH services at low, posted prices. In this case, subsidies for the poor are delivered centrally through the franchise: defraying the operational costs of training, supplying and managing the network, but not directly financing RMPs, thereby avoiding the need to verify service delivery qualities directly. 15

Similarly, in Peru the RedPlan Salud franchise provides safe delivery, family planning and other SRH services through a network of private doctors and midwives located in low-income areas. External funding is directed to the franchise, allowing it to subsidise the for-profit providers through support, supplies, training and advertising, allowing them to be profitable even while charging low prices to poor consumers. ${ }^{16}$

\section{Innovations in financing of government-provided care}

Contracting and expanding social health insurance are the two areas where innovative programmes are extending government-supported access and equity for SRH services. ${ }^{17}$

Some countries have expanded service coverage by using NGO or faith-based organisation (FBO) resources as a de facto extension of government health resources. The Christian Health Association of Ghana (CHAG) has such a relationship with the government through which they receive staff, training, pharmaceuticals and other support. Although operated independently, the providers and facilities of CHAG are perceived by the government, and often by CHAG staff, to be de facto branches of the national programmes.

A limited number of health ministries in low- and middle-income countries have effectively divided the specialised management functions of service financing, delivery and oversight. For those that have accomplished this, whole areas of service expansion and gains arise from competition. The examples of Profamilia in Columbia and Banja La Mtsogoloa in Malawi provide illustrations of what can be achieved for SRH services through centralised innovation that allows external contracting with multi-site organisations. ${ }^{18}$ In both examples, contracted out services were initially limited to family planning, but in parts of Columbia the contract to Profamilia has expanded to include a wide range of services.

More radically, health ministries can contract out services directly to private practitioners. While this is common in Germany, the UK or the USA, it is new in developing countries. The Chiranjeevi Yojana programme in Gujarat, India has enrolled nearly all private rural obstetricians/gynaecologists in its pilot regions and pays them a flat rate reimbursement for all deliveries to women registered as below the poverty line. By offering all poor women access to the level of medical care provided to the higher-income groups in their districts, Chiranjeevi Yojana has successfully reduced maternal and child mortality rates. 19

In Nicaragua, the Empresas Medicas Previsionales programme works under the auspices of the national social security institute, INSS. The programme gives loans to private clinics to upgrade the quality of services, particularly for SRH, and then contracts them to provide population-level coverage of those services through the INSS. ${ }^{18}$

In Nigeria, the National Health Insurance Scheme is piloting coverage expansion by contracting service delivery to private insurers or health maintenance organisations (HMOs), which then contract to private providers and clinic groups. ${ }^{18}$ A similar national health insurance programme in The Philippines, PhilHealth, has been well received and successful at increasing overall health coverage.

\section{Innovations in subsidy delivery}

Once a population of at-risk or disadvantaged individuals has been identified, assuring the delivery of services to that group remains a challenge. One approach is demand side financing in which subsidies are provided not to the service deliverers (clinics, hospitals, HMOs, etc), but to the patients: the demand side of the health service transaction. These subsidies are difficult to monitor, open to problems of corruption, and face a significant education hurdle to assure that beneficiaries understand the subsidies being offered. Once all of these issues are addressed, demand side subsidies can change patient health-seeking behaviour and may offer a larger potential for population benefit than supply side programmes.

There are several different types of demand side financing. Cash transfers are common in many countries, and include income support, child grants, disability benefits, scholarships and pensions. Voucher programmes are a form of demand side financing that transfer a subsidy to targeted individuals, which can then be used in exchange for specific products or services. Incentive-based voucher schemes provide a subsidy directly to recipients to encourage a specific behaviour or reduce the cost of a given service. Conditional cash transfers are a type of incentive-based voucher scheme demonstrated to have had an effect on a large scale in Mexico. 20

In Kenya and Uganda, Kreditanstalt für Wiederaufbau (KfW) and the World Bank are mounting two large pilot programmes for RH services and STI treatment, using vouchers to link subsidies to specific services. ${ }^{21,22}$ In Nicaragua, STI voucher programmes were started by the Central American Health Institute (ICAS) during the early 1990s and showed strong, if small-scale, successes. ${ }^{23}$ Two of the most successful national family planning programmes in the 1960s and 1970s, in Taiwan and South Korea, were both based upon voucher systems that targeted subsidies to specific services, but were effectively agnostic about where those services were delivered. It is not yet clear how to bridge the gap between the small-scale, highcost, programmes in Nicaragua and Uganda and the nationwide programmes of four decades ago in Asia, and Mexico today.

\section{Innovations in sustainability}

SRH services are not well suited to sustainability. Pressure from donors to demonstrate sustainability can have a damaging effect when demand is fragile. ${ }^{24}$ With a few exceptions (deliveries, abortion, treatment of HIV/AIDS or advanced reproductive tract infections) the provision of SRH services cannot produce high profit margins for clinicians. Family planning services and disease testing services in particular have low base costs and therefore small mark-up value, often compete with free government provision and, as with all preventative services, have high price elasticity so that any attempt to increase prices will result in decreased demand, again challenging margins. 
Where such margins do exist, invariably there is a conflict with equity unless a sufficiently diversified range of services can be offered, allowing a degree of internal cross-subsidisation. In this context, the strategies applied by those institutions capable of making SRH service delivery both equitable and financially sustainable are of great interest.

In 1989, the World Health Organization formally endorsed a model of rotating drug funds codified in the Bamako Initiative. Since then, it has become recognised that assuring the sustainability of lower-level services for low-income populations needs a more nuanced approach to encompass cross-subsidisation from more profitable services with lower social value to loss-making, high social-value services. This may be simple in theory but is difficult in practice. The revolving medical funds of Pro Redes Salud in Guatemala are attempting this through a two-stage division of responsibility where NGOs deliver services and the revolving drug fund supplies the NGOs at cost; some NGOs added profit-making services (e.g. laboratory diagnostics) to become self-funding, while others continue to be subsidised by the Pro Redes Salud initially, and now by the Ministry of Health. ${ }^{18,25}$ In Kenya, the Mission for Essential Drugs and Services (MEDS) operates similarly: not profiting but selling at a costcovering margin to non-profit clinics on a larger scale that includes all essential medicines. Like Pro Redes Salud, MEDS is a non-profit entity. Critical to the success of MEDS is the ongoing and significant relationship between MEDS, its suppliers, and the NGOs and Mission Hospitals that MEDS supplies. The transparency of each of these interactions assures trust, which is critical for MEDS, as its products are sold below market cost and would, if distributed freely beyond the NGO community, erode profitable markets of MEDS's pharmaceutical suppliers.

While MEDS and Pro Redes Salud focus on an application of risk pooling so as to achieve lower average costs for pharmaceuticals, a number of other initiatives are looking to achieve sustainability through diversification of income streams - subsidising SRH services through profitable non-SRH services. The Clinix Health Group in South Africa and the Bushenyi Medical Centre in Uganda are both examples of networked private clinics that provide a range of for-profit inpatient and outpatient care, including SRH services, that are able to sustain service delivery for SRH because of the income from a diversified portfolio of care. ${ }^{18}$ Both focus on serving low-income populations which they target by placing their clinics in poor areas. In Nicaragua, Profamilia clinics achieved full cost-recovery by expanding the range of services provided in each clinic to include high-end services such as X-ray, mammography and surgeries. 18

These examples demonstrate both the potential of achieving sustainable funding through better cost spreading and risk pooling, and also how difficult this can be. The programmes described above differ from place to place and replication across national borders has either failed or required significant reworking of the model to adapt to local conditions.

\section{Conclusions}

The challenges for the delivery of SRH services in developing countries that are both sustainable and equitable are not easily overcome. While some funding initiatives have proven themselves capable of withstanding political changes, this is not always the case, and priorities unrelated to health or equity drive many international and national funding decisions. Because of this, much of the innovation in this area has focused on resource pooling and on purchasing or subsidising SRH services. Within these broad categories there are a number of initiatives that have taken steps towards addressing equity and sustainability issues. While no "one-size-fits all" solution exits, there are numerous ongoing examples of successful innovations in targeting, expansion of government services, subsidy delivery and sustainability. For most of these, information on long-term success is not available, precisely because the ideas being tested are new. They nonetheless provide encouragement and a strong foundation from which to make advances in this field.

How SRH services are financed is central to assuring equity and access and must be the starting point for design and assessment of new and existing programmes. The examples above provide some indications of what can be done.

\section{Acknowledgements}

The authors thank Dale Huntington of the World Health Organization and the two anonymous expert reviewers for the Journal of Family Planning and Reproductive Health Care for their contributions.

Statements on funding and competing interests

Funding None identified.

Competing interests None identified.

\section{Editor's note}

Readers may also be interested in the Commentary article on page 143 of this journal issue since this explores a number of themes related to this article.

\section{References}

1 Ciszewski RL, Harvey PD. Contraceptive price changes: the impact on sales in Bangladesh. Int Fam Plann Perspect 1995; 21: 150-154.

2 Fathalla MF, Sinding SW, Rosenfield A, Fathalla MMF. Sexual and reproductive health for all: a call for action (Sexual and Reproductive Health Series 6). Lancet 2006; 368: 2095-2100.

3 Blane J, Friedman M. Mexico City Policy Implementation Study. Dual and Associates, Inc., International Science and Technology Institute, Inc., Population Technical Assistance Project Occasional Paper No. 5. 1990.

4 Population Crisis Committee. Impact of the Mexico City Policy on Family Planning Programs and Reproductive Health Care in Developing Countries. Washington, DC: Population Crisis Committee, 1988.

5 UNFPA \& NIDI. Trends in ICPD Categories. The Resource Flows Project. http://www.resourceflows.org/index.php/articles/ c78/ [Accessed 17 October 2008].

6 UNFPA Global Population Policy Update, No. 54. 22 July 2005. http://www.unfpa.org/parliamentarians/news/newsletters/issue 54.htm [Accessed 17 October 2008]

7 Retail sales and fee-for-service providers. Population Reports, 1 November 1991.

8 El-Rafaey H, Rodeck C. Post-partum hemorrhage: definitions, medical and surgical management. A time for change. $\mathrm{Br} \mathrm{Med}$ Bull 2003; 67: 205-217.

9 World Health Organization (WHO). Reduction of Maternal Mortality: A Joint WHO/UNFPA/World Bank Statement. Geneva, Switzerland: WHO, 1999; 11.

10 World Health Organization (WHO). Maternal Mortality in 2005 : Estimates Developed by WHO, UNICEF, UNFPA and The World Bank. Geneva, Switzerland: WHO, 2007.

11 Decker M, Montagu D. Reaching youth through franchise clinics: assessment of Kenyan private sector involvement in youth services. J Adolesc Health 2007; 40: 280-282.

12 Murray NJ, Dougherty L, Stewart L, Buek K, Chatterji M. Are Adolescents and Young Adults More Likely Than Older Women to Choose Commercial and Private Sector Providers of Modern Contraception? DHS Report 2005. http://www.policyproject. $\mathrm{com} /$ pubs/generalreport/contraception_sources.pdf [Accessed 17 October 2008]

13 Oeun SS. Equity Fund Program - Kirivong Operational Health District, Cambodia. A presentation for Vouchers for Health: Increasing Access, Equity, and Quality in Gurgaon, India, 12-13 April 2007. http://www.psp-one.com/content/resource/ detail/4002/ [Accessed 17 October 2008]

14 Stjernswärd J. Uganda: initiating a government public health approach to pain relief and palliative care. J Pain Symptom Manage 2002; 24: 257-264. 
15 Gopolakrishnan G. Janani's Programme in Bihar: An Update. A presentation for the 5th Annual Meeting of Alternative Business Models for Family Planning in California, CA, USA, 7-8 October 2004. http://www.cpc.unc.edu/projects/abm/ Presentations5/gopalakrishnan.pdf [Accessed 17 October 2008].

16 Aspilcueta D. Managing to Scale: The Case of RedPlan Salud (RPS). A presentation for the WHO Meeting on Social Franchises: Technical Consultation Meeting. Public Policy and Reproductive Health Franchising: Current Evidence and Future Directions in Geneva, Switzerland, 6-8 December 2006. http://www.who.int/reproductive-health/tcc/presentations/ aspilcuetta.ppt [Accessed 17 October 2008].

17 World Health Organization. Improving Health Services and Strengthening Health Systems: Adopting and Implementing Innovative Strategies (Making Health Systems Work Series. Working Paper \#5). 2006. http://www.who.int/management/ mhswork/en/index.html [Accessed 17 October 2008].

18 Chandani T, Sulzbach S. Private Provider Networks: The Role of Viability in Expanding the Supply of Reproductive Health and Family Planning Services. Bethesda, MD: Private Sector Partnerships-One Project, Abt Associates Inc., April 2006. http://www.psp-one.com/content/resource/detail/2941/ [Accessed 17 October 2008].

19 Singh A. Chiranjeevi: Involving private obstetricians to reduce maternal mortality in Gujarat (India). A presentation for the GHC expert panel "Making it Work: Private Sector Partnerships to Improve Women's Health". 2007. http://www. hrhresourcecenter.org/node/1551 [Accessed 17 October 2008]

20 Rivera JA, Sotres-Alvarez D, Habicht JP, Shamah T, Villalpando S. Impact of the Mexican program for education, health, and nutrition (Progresa) on rates of growth and anemia in infants and young children: a randomized effectiveness study. JAMA 2004; 291: 2563-2570.

21 Kundu F. Reproductive Health - Output Based Approach Project (Kenya). A presentation for Vouchers for Health: Increasing Access, Equity, and Quality in Gurgaon, India, 12-13 April 2007. http://www.psp-one.com/files/4007 file Francis_Kundu_Kenya_country_1.pdf [Accessed 17 October 2008].

22 Bellows B. Evaluating a Voucher Program for Treatment of Sexually Transmitted Infections (STIs) in Uganda. A presentation for Vouchers for Health: Increasing Access, Equity, and Quality in Gurgaon, India, 12-13 April 2007. http://www.psp-one.com/section/technicalareas/health finance/vouterworkshop2/voucherworkshop [Accessed $1 \overline{7}$ October 2008].

23 Borghi J, Gorter A, Sandiford P, Segura Z. The Costeffectiveness of a Competitive Voucher Scheme to Reduce Sexually Transmitted Infections in High-risk Groups in Nicaragua. Oxford University Press in association with The London School of Hygiene and Tropical Medicine and Instituto Centroamericano de la Salud, Managua, Nicaragua, 2005.

24 Langer A, Nigenda G, Catino J. Health sector reform and reproductive health in Latin America and the Caribbean: strengthening the links. Bull World Health Organ 2000; 78: 667-676.

25 NGO Networks Project, Pro Redes Salud. Final Report 2004. John Snow Research \& Training Institute. http://www.jsi.com/ Managed/Docs/Publications/WomensHealth/PDACA603.pdf [Accessed 17 October 2008].

FICTION BOOK REVIEW

Tell It To The Bees. Fiona Shaw. Birmingham, UK: Tindal Street Press, 2009. ISBN-13: 978-0955647-66-6. Price: £9.99. Pages: 304 (paperback)

The book is set in the 1950s. Lydia works in the local factory but unlike most of her workmates loves to read. She is married to Robert, an attractive but self-centred man, who has started to stray since the arrival of their son Charlie, partly because of the insinuations of his elder sister who loves him possessively. This sister brought him up and her dislike of Lydia will make readers recollect many similar relationships.

Charlie, Lydia's son, is taunted at school by a group of girls, who know what his father is up to. Charlie's character and reactions are excellently drawn, so that you can imagine exactly how he feels, withdrawing into himself, wary at home, with only the one friend, Bobby, at school. Eventually, Charlie is goaded too far in the playground and goes whirling into action, fighting everyone in his way.

Charlie's cautious movements of his injured ribs cause his mother to worry. She persuades her husband to take him to see the local female GP, Jean. The readers have already had a picture drawn of this tall, intense woman, determined to make her way as a doctor in the $1950 \mathrm{~s}$, despite the antagonism of her family and the prejudices of the local population. The graphic description of her life gives a good sense of the isolation and difficulties in single-handed practice of that time, particularly for a woman. Jean's only consolation is her bees to whom she confides.

While in the consulting room, Charlie sees a wooden carving of a honeycomb. Jean notices his interest and suspecting that his injuries were not caused, as Charlie said, by falling over, offers to show him her bees. Charlie visits her and gradually becomes more involved in the care of the bees. Jean invites Lydia to visit and discovers her love of books - and Jean has a large library of books that she never has time to open. Jean is also excited to have met this unusual, and attractive, woman. She lends books to her and a friendship develops.

Lydia's husband leaves to take up with another woman, encouraged by his sister. $\mathrm{He}$ ceases to pay the rent and despite working even longer hours at the factory, Lydia cannot keep up the payments and is about to be thrown out onto the street. Jean's housekeeper wants to leave and Jean asks Lydia and Charlie to live with her. The relationship between the two women develops into a passionate one - the connecting door between two bedrooms keeping the fiction of propriety. One night, during a thunderstorm, Charlie wakes and goes into his mother's bedroom to find her bed empty. Although she returns swiftly on hearing him, the damage is done. Charlie innocently tells his cousin about it and is overheard by his aunt, Robert's sister. She immediately understands the significance of the event and plots to shame and humiliate Lydia. Robert turns up at school and collects his son, taking him to his new partner. Charlie appears passive, unable to understand what these strange adults are doing, only knowing that he is unhappy and that his mother will be too.

Lydia retreats into blankness and Jean takes would not allow a mother in a lesbian relationship to have custody of a child. The terrible longing, the grief and anger are heart-rending. The ending is a little contrived but the twist of circumstances will have you turning each page until the end.

What will health professionals in particular gain from this excellent page-turner? Insights into the mind of a child baffled and distressed by adult behaviour; the passionate nature of Lydia, leading her into unwise relationships; the emotional neediness of a single-handed, female GP in the 1950s; the antagonism towards lesbian love (which still exists but less overtly); the destructive possessiveness of, in this case, a sister; attitudes towards pregnancy out of wedlock in the 1950s; and many more. The author has been able to portray so many facets of human nature and relationships that every reader should gain in empathy.

Reviewed by Gill Wakley, MD, FFSRH Retired Professor of Primary Care Development and Freelance Writer, Abergavenny, UK

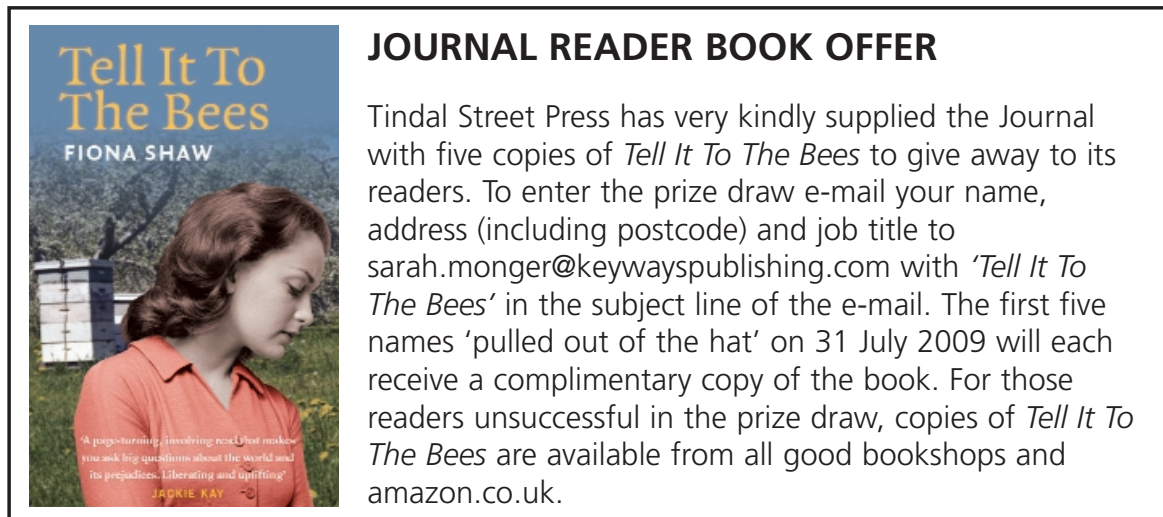

We hope that journal readers enjoyed reading Tell It To The Bees, and also discovering whether their opinion of the book matched that of our guest reviewer. In the October 2009 issue, the fiction book under scrutiny will be Tomorrow by Graham Swift (256 pages, Picador, 2008, ISBN-13: 978-0330450263).

We want to remind journal readers that if they would like to offer to review an appropriate fiction title of their own choosing then they should contact the Journal Editorial Office by e-mail (journal@fsrh.org) in the first instance with details of their nominated title. 